\title{
Japanese universities are slow to welcome foreign faculty
}

Tokyo. Members of Japan's ruling Liberal Democratic Party (LDP) have joined a chorus of voices calling for a dramatic increase in the number of foreign faculty members in national universities. An LDP project team led by Noriaki Watase submitted its recommendations earlier this month to two LDP committees on academic and cultural affairs, and last week a committee of academics that advise the Ministry of Education, Science and Culture (MESC) made a similar recommendation.

Despite this growing pressure, Japan's universities will probably be slow to change their employment practices. Although universities have since 1982 been allowed to hire non-Japanese professors, associate professors and lecturers, the number of such foreign faculty today stands at only 201 , or 0.5 per cent of the approximately 37,000 faculty in Japan's 98 national universities.

Of these foreigners, only 17 enjoy permanent employment (tenure) like their Japanese colleagues (see table). The rest are on temporary appointments, which are limited to a specified number of years (with the possibility of extension if their performance is good).

Furthermore, almost half of those with tenure have strong personal links to Japan. Eight are graduates of Japanese universities, two of the Koreans with tenure were born and educated in Japan and two other faculty members are of Japanese ancestry. Only four Western academics have tenure, and for two of them their speciality is teaching their native language.

The release of the LDP recommendations was followed a week later by a report from a committee of the University Council, a body of senior academics that advises MESC. Calling for more open employment practices in Japan's universities, the report says that more foreign faculty should be hired and that the terms of their employment should be adapted to individual needs.

The LDP and University Council recommendations echo the views of a team of

foreign and Japanese scientists who earlier this year proposed employment of more foreign faculty in an external review of the physics department of Tokyo University (see Nature 362, 387; 1993). Among the national universities, Tokyo is the most progressive; it employs the largest number of foreign faculty, 13 , and has given tenure to nearly half of them. Nevertheless, only a handful are scientists or engineers.

"In principle I agree completely with these [LDP] recommendations", says Akito Arima, former president of Tokyo University who retired from the university shortly after the external review was completed in March. "But in practice it will be very hard to do. Not so many foreign scientists want to stay in Japan. And there are many problems such as lack of international schools for their children and lack of suitable accommodation". Other leading Japanese academics say that institutions are wary of hiring foreign faculty because it is difficult for them to participate in meetings and join committees if they cannot speak and write Japanese.

"The language problem is real", says Robert Geller, a US geophysicist at Tokyo University and one of the few foreign faculty with tenure. "But it should not be used as an excuse. Foreigners new to Japan can make significant contributions to committees dealing with international issues and they can help in the production of English reports." Geller, who has lived in Japan for several years and who speaks and writes Japanese, has served on several faculty committees.

Geller says that the dearth of foreigners is closely related to the "lack of Japanese from other universities" on any faculty. Departments typically choose new faculty members from among their own students and there is very little movement between universities. For example, in Tokyo University's faculty of engineering, 99 per cent (998) of the 1,010 faculty members are graduates of Tokyo University. Such inbreeding needs to be eliminated before a significant influx of foreigners can be achieved, says Geller. Another obstacle is the small number of women faculty members in Japanese universities.

Although individual faculty members play an important role in bringing about change, there is also a need for the large number of universities that do not offer tenure to revise their internal regulations to allow employment of foreigners on equal terms. MESC, which administers the universities, must also provide strong leadership, an ingredient that so far seems lacking. Commenting before the release of the University Council report, Yoshikazu Hasegawa, director of the ministry's science and international affairs bureau, said about the LDP recommendations that "we will treat the suggestions of the legislature with respect, but we will not necessarily say yes to everything".

David Swinbanks 